\title{
Effect of controlled rolling/controlled cooling parameters on microstructure and mechanical properties of the novel pipeline steel
}

\author{
Min Jiang $\cdot$ Li-Na Chen $\cdot$ Jin He $\cdot$ Guang-Yao Chen • \\ Chong-He Li $\cdot$ Xiong-Gang Lu
}

Received: 20 December 2013/ Accepted: 12 June 2014/Published online: 19 July 2014

(C) Shanghai University and Springer-Verlag Berlin Heidelberg 2014

\begin{abstract}
The study of controlled rolling/controlled cooling process parameters which affect the microstructure and mechanical properties of a novel pipeline steel have been optimized by the orthogonal experiment with four factors and three levels in this paper. However, the parameters of thermo-mechanical control process (TMCP) optimized by the Gleeble-3500 hot simulator could not satisfy performance requirements of the X100 pipeline steel. In order to improve the performance of this steel, the influence of finish cooling temperature (FCT) on the microstructure and property is studied in detail. It is found that, as this steel is thermo-mechanically treated by this set of parameters (the start heating temperature, finish rolling temperature (FRT), FCT and cooling rate of $1,180{ }^{\circ} \mathrm{C}$, $810^{\circ} \mathrm{C}, 350{ }^{\circ} \mathrm{C}$ and $35^{\circ} \mathrm{C} / \mathrm{s}$, respectively), the microstructures are mainly composed of granular bainite (GB) and acicular ferrite (AF). The effective grain sizes are below $20 \mu \mathrm{m}$; the steel reached the optimal balance between the strength and the toughness; the yield strength
\end{abstract}

M. Jiang · L.-N. Chen · J. He · G.-Y. Chen · C.-H. Li (凹) · X.-G. Lu

Shanghai Key Laboratory of Modern Metallurgy \& Materials Processing, Shanghai University, Shanghai 200072, People's Republic of China

e-mail: chli@staff.shu.edu.cn

M. Jiang

Baoshan Iron \& Steel Co., Ltd., Shanghai 200940, People's

Republic of China

C.-H. Li · X.-G. Lu

Shanghai Special Casting Engineering Technology Research

Center, Shanghai 201605, People's Republic of China is $695 \mathrm{MPa}$; the tensile strength is $768 \mathrm{MPa}$; the elongation is $16.6 \%$; the impact energy is $262 \mathrm{~J}$ at room temperature. All indexes could meet the requirements of X100 pipeline steel.

Keywords Controlled rolling/controlled cooling · Finish cooling temperature (FCT) $\cdot$ Microstructure $\cdot$ Mechanical properties $\cdot$ X100 pipeline steel

\section{Introduction}

In the modern pipeline technology, much effort has been devoted on the strength, toughness and corrosion resistance of pipeline steel to increase its properties. Recently the transportation of crude oil or natural gas requires the steel with higher strength, toughness and good formability to get a reliable and safer access to energy [1]. Therefore, the development of novel pipeline steel attracted the attention of the engineers around the world [2]. Usually, the mechanical property of pipeline steel is determined by the proportion of multiple microstructures, which include polygonal ferrite $(\mathrm{PF})$, acicular ferrite $(\mathrm{AF})$, granular bainite (GB) and lathbainite (LB) with different technological processes [3]. Table 1 lists the general requirements of X100 pipeline steel in the engineering application [4]. The development and progress of the pipeline steel shows that the best combination of alloy composition design, metallurgical technology, controlled rolling and controlled cooling will determine the comprehensive performance of steel.

Currently, thermal-mechanical control process (TMCP) has been widely applied to control the grain structure in industrial production. For example, Gómez analyzed the evolution of microstructure and precipitation state of high- 
Table 1 The general requirements of X100 pipeline steel in engineering application

\begin{tabular}{lllll}
\hline$\sigma_{b} /$ & $\sigma_{\mathrm{s}} l$ & $\delta$ & $\begin{array}{l}\text { Charpy V-notch impact } \\
\text { toughness/J }\end{array}$ & $P_{\mathrm{cm}}$ \\
$\mathrm{MPa}$ & $\mathrm{MPa}$ & & & \\
\hline$>760$ & $>695$ & $>15 \%$ & $>250$ & $<0.20$ \\
\hline
\end{tabular}

level pipeline steel through TMCP process [5], in which the effects of processing parameters of TMCP [6], such as finish cooling temperature (FCT), finish rolling temperature (FRT) and coiling temperature on the microstructure and mechanical properties of low C-Mn steel were reported. Furthermore, Wang investigated that all strengthening types of fine grain precipitation and phase transformation could be obtained by TMCP. Therefore the alloy contents could be saved over $30 \%$; the strength of steel products could be increased by over 100-200 MPa; the energy could be reduced by $10 \%$ [7].

In order to produce higher strength and toughness pipeline steel, the alloy design must be reasonably done. The pipeline steel is one of the most successful applications using the micro-alloying theory. Adding an appropriate amount of alloying elements $\mathrm{Nb}, \mathrm{V}, \mathrm{Ti}$ and $\mathrm{Ni}$ to general $\mathrm{C}-\mathrm{Mn}$ steel makes the final grain of steel fine and improves the strength and toughness of the steel $[8,9]$. The studies on the low carbon and high manganese of high-level pipeline steel attracted more and more attention. For example, Gao reviewed in details the development of pipeline alloy design-micro-alloying of low carbon or ultralow carbon and multi-alloying [10]. Wang and $\mathrm{Lu}$ [11] also systematically summarized the basic design idea aiming at developing the pipeline steel with better comprehensive properties.

In this work, one novel pipeline steel is suggested according to the current literature using the Gleeble- 3500 hot simulator. The parameters of the TMCP including heating temperature, FRT, FCT and cooling rate are optimized by the orthogonal experiment with four factors and three levels. However the steel prepared by the optimum processing parameters of TMCP obtained by Gleeble- 3500 hot simulator cannot meet the performance requirement of the X100 pipeline steel. Due to the key effect of the FCT on the microstructure and property of the pipeline steel, the influence of FCT will be further investigated. The final goal is to squeeze out a set of TCMP parameters, by which the steel can reach the standard of the X100 pipeline steel.

\section{Experimental}

\subsection{Chemical composition of pipeline steel}

The steel was melted in $50 \mathrm{~kg}$ vacuum induction furnace in the laboratory, and then was forged into $80 \mathrm{~mm} \times 80 \mathrm{~mm}$ square billet. Table 2 lists the chemical composition of novel pipeline steel.

\subsection{Thermal-mechanical simulation test}

Nine steel specimens with a size of $\Phi 10 \mathrm{~mm} \times 15 \mathrm{~mm}$ were cut from cast slabs and hot compressed to a cylinder with $4 \mathrm{~mm}$ in height through a two-stage controlled rolling process. It was well-known that, the factors such as the heating temperature,FCT, FRT and cooling temperature would mainly determine the microstructures and properties of pipeline steels [6]. Therefore, these four factors were used to build up the $\mathrm{L} 9\left(3^{4}\right)$ orthogonal table [12] for the Gleeble-3500 hot simulator in this study, as shown in Table 2.

\subsection{Pilot rolling experiment}

The hot rolling specimens with a size of $27 \mathrm{~mm}$ in thickness, $80 \mathrm{~mm}$ in width and $100 \mathrm{~mm}$ in length were cut from cast slabs. The optimum processing parameters of TMCP obtained from the Gleeble-3500 hot simulator were applied to the rolling experiment conducted in the laboratory.

\subsection{Mechanical properties}

Specimens for the tensile and impact tests were cut from the middle of the rolled plates in the transversal direction. The sample for tensile tests was prepared according to GB/ T 228-2002, and the tensile tests were conducted at room temperature in a CMT5305 servo-hydraulic machine. To evaluate the charpy impact energy, the sub-size specimens $(10 \mathrm{~mm} \times 10 \mathrm{~mm} \times 55 \mathrm{~mm})$ with a $\mathrm{V}$ type notch were tested at room temperature with the standard method in a JB-6(80A00277) type impact testing machine. The

Table 2 Chemical composition of the novel pipeline steel

\begin{tabular}{|c|c|c|c|c|c|c|c|c|c|c|}
\hline Element & $\mathrm{C}$ & $\mathrm{Mn}$ & $\mathrm{Si}$ & $\mathrm{S}$ & $\mathrm{P}$ & $\mathrm{Nb}$ & Mo & $\mathrm{Ni}$ & $\mathrm{Ti}$ & $\mathrm{Al}$ \\
\hline Content/wt $\%$ & 0.060 & 1.28 & 0.25 & 0.0017 & 0.016 & 0.053 & 0.31 & 1.30 & 0.012 & 0.0075 \\
\hline
\end{tabular}


hardness of the samples was measured by the Rockwell hardness tester HRB69-1.

\subsection{Microstructure of the hot simulation and the hot rolled specimens}

Microstructures of the hot simulation and the hot rolled specimens were examined by the optical microscope (OM, Leca), the scanning election microscopy (SEM, JSM6700F) and the energy dispersive spectrometer.

\section{Results and discussion}

\subsection{Thermal-mechanical simulation of TMCP process}

Nine steel specimens with the size of $\Phi 10 \mathrm{~mm} \times 15 \mathrm{~mm}$ are cut from cast slabs and final hot rolled to a cylinder with a height of $4 \mathrm{~mm}$ through a two-stage controlled rolling process, as shown in Fig. 1.

The results of the experiments and the analysis of orthogonal test are shown in Table 3.

Figure 2 shows the optical micrographs $(a-i)$ of the specimens of hot simulation.

The hardness values of nine hot simulation specimens, HRB, were measured and listed in Table 2. The hardness of group e reached 101.5 HRB, which was significantly higher. For the simplicity, we measured the hardness instead of the strength according to GB/T 1172-1999 [13]. Generally, the strength is directly proportional to the hardness and the strength increases as the hardness increases. It may be reasonable to consider that the strength of group e may be higher than other groups.

Usually, the microstructure of pipeline steel is a multiphase structure, including AF, LB, PF, GB, among which the AF can guarantee that the steel will have a higher toughness at low temperature and low ductile to brittle transition temperature without a falling in strength. Finally it greatly improves the service life of pipeline steel. Therefore, the main developing trend of modern high performance pipeline steel is how to get the microstructure with AF.

The nucleation of AF is attached to the existing interface, which is mainly provided by non-metallic inclusions [14] (such as titanium oxides). Meanwhile the residual distortion energy produced by the rolling process also promotes the nucleation of $\mathrm{AF}$ in our experiment. The microstructures of the hot simulation specimens at different process parameters are shown in Fig. 2. The optical micrographs (see Figs. 2a-i) are obtained under the processing parameters, as shown in Table 3 . Then the effects of the start heating temperature, FRT, FCT and the cooling rate on the microstructure will be discussed in detail.

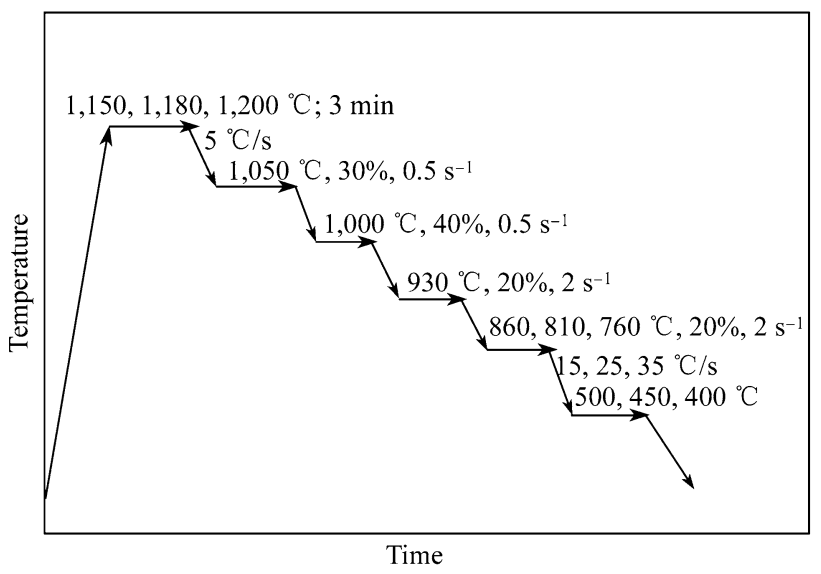

Fig. 1 The schematic of the thermo-mechanical treatments

Table 3 The analysis of orthogonal test

\begin{tabular}{lllllr}
\hline $\begin{array}{l}\text { Level } \\
\text { temperature } /{ }^{\circ} \mathrm{C}\end{array}$ & $\begin{array}{l}\text { Heating } \\
{ }^{\circ} \mathrm{C}\end{array}$ & $\begin{array}{l}\text { Cooling rate/ } \\
\left({ }^{\circ} \mathrm{C} \cdot \mathrm{s}^{-1}\right)\end{array}$ & $\begin{array}{l}\text { FCT/ } \\
{ }^{\circ} \mathrm{C}\end{array}$ & HRB \\
\hline $\mathrm{a}$ & 1,150 & 860 & 15 & 400 & 84.1 \\
$\mathrm{~b}$ & 1,150 & 810 & 25 & 450 & 90.0 \\
$\mathrm{c}$ & 1,150 & 760 & 35 & 500 & 88.4 \\
$\mathrm{~d}$ & 1,180 & 860 & 25 & 500 & 90.5 \\
$\mathrm{e}$ & 1,180 & 810 & 35 & 400 & 101.5 \\
$\mathrm{f}$ & 1,180 & 760 & 15 & 450 & 85.2 \\
$\mathrm{~g}$ & 1,200 & 860 & 35 & 450 & 82.8 \\
$\mathrm{~h}$ & 1,200 & 810 & 15 & 500 & 80.8 \\
$\mathrm{i}$ & 1,200 & 760 & 25 & 400 & 92.1 \\
\hline
\end{tabular}

These microstructures at cooling rate of $15{ }^{\circ} \mathrm{C} / \mathrm{s}$ are similar to Duan's results [15], which are largely composed of the AF together with the LB, as shown in Figs. 2a, f, h. The $\mathrm{AF}$ is an acicular microstructure formed inside austenite grains and contains martensite austenite (MA) constituents at irregularly shaped grain boundaries. Small amounts of austenite grain boundaries are found around LB. LB grains are relatively large and its grain boundaries cannot be identified clearly. The microstructures of the specimens are heterogeneously dispersed, and the distance of AF is quite large. For specimens that are composed of PF together with LB at a cooling rate of $25^{\circ} \mathrm{C} / \mathrm{s}$ (see Figs. 2b, d, i), the amount of LB decreases. $\mathrm{PF}$, which is transformed at the highest temperature, is an equiaxed microstructure and plate-like in shape. Compared with the specimen at a cooling rate of $15{ }^{\circ} \mathrm{C} / \mathrm{s}$, the size of grain is smaller. The specimens that are composed of the GB together with $\mathrm{LB}$ at cooling rate of $35^{\circ} \mathrm{C} / \mathrm{s}$ are shown in Figs. 2c, e, g. The GB contains the equiaxed MA constituents, and has well-developed substructures inside. The GB grains which are smaller than $10 \mu \mathrm{m}$ in size are homogeneously dispersed. Its grains are relatively small and its grain boundaries are clearly identified. 

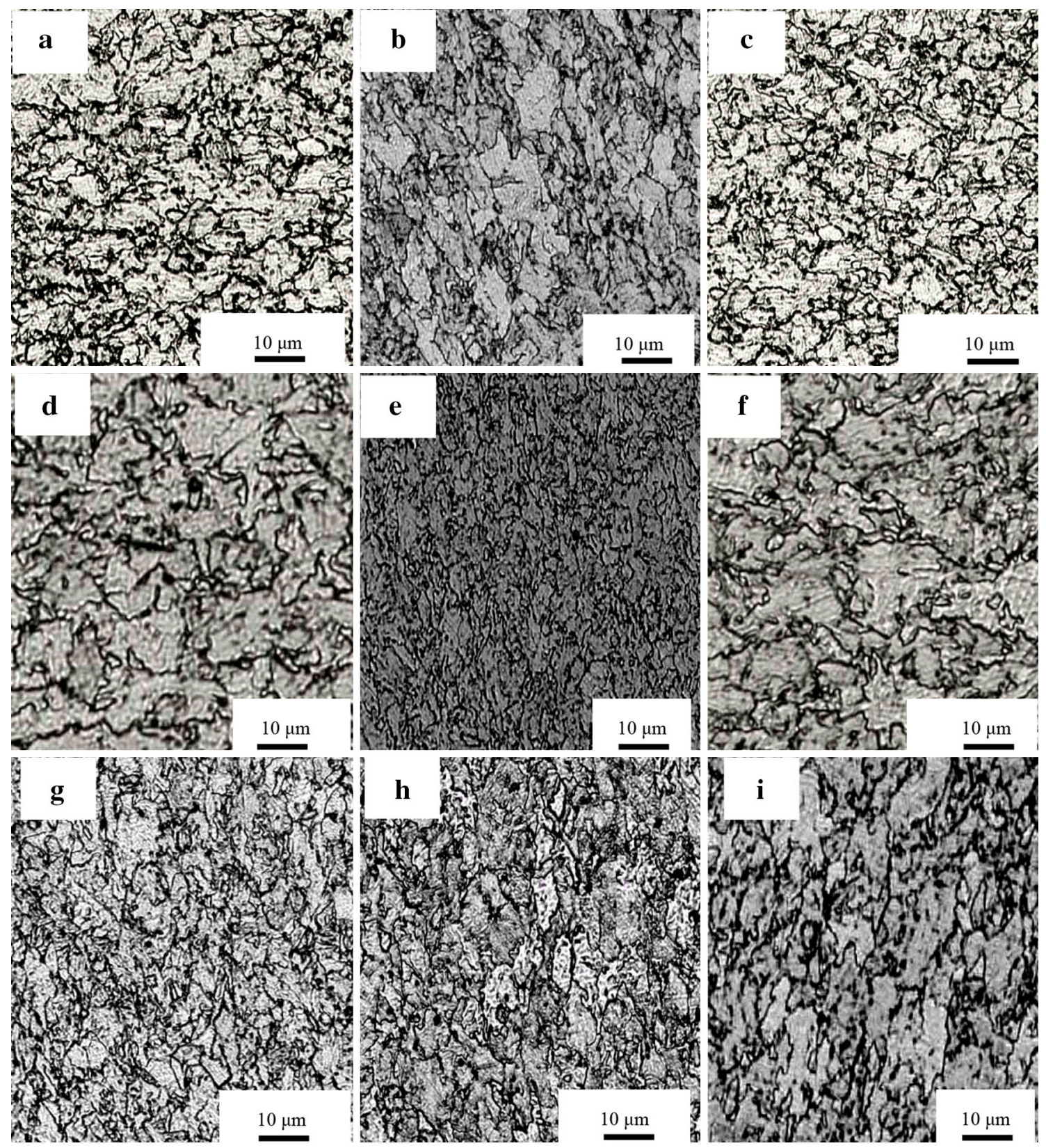

Fig. 2 The optical micrographs $(\mathbf{a}-\mathbf{i})$ of the specimens of hot simulation

At the FCT of $400{ }^{\circ} \mathrm{C}$ (see Figs. 2a, e, i), PF is rarely observed with rapid cooling rate because a few hightoughness AFs are formed. A hard phase, such as MA, is formed coarsely. When FCT increases to about $450{ }^{\circ} \mathrm{C}$ (see Figs. 2b, f, g), specimens are largely composed of GB. High-toughness ferrite colonies increase in volume. When the FCT increases to higher than $500{ }^{\circ} \mathrm{C}$ (see Figs. 2c, d, h), AF and GB are primarily observed. With increasing FCT, high-toughness phases are formed coarsely and hard phases tend to be reduced in their sizes and are distributed homogeneously. This leads to low strength with good toughness [16].
When the FRT is $810^{\circ} \mathrm{C}$ (see Figs. $2 \mathrm{~b}$, e, h), the microstructure is composed of LB, GB and AF. When FRT increases to $860{ }^{\circ} \mathrm{C}$ (see Figs. 2a, d, g), the microstructure is largely composed of GB and AF. Much high-toughness $\mathrm{AF}$ is formed. With increasing FRT, more AF observed leads to low strength [17]. The role of FRT on mechanical properties of the steel may be attributed to the acceleration of transformation and the refinement of grains by the reduction of FRT [18]. Therefore, the reduction of FRT will be beneficial to both strength and ductility. It has been reported [19] that when FRT is over a certain temperature (about $840{ }^{\circ} \mathrm{C}$ ), both yield strength and toughness of the 
Table 4 The inter-pass reduction distribution for the hot rolling experiment

\begin{tabular}{llllll}
\hline Parameters & Value & & & \\
\hline Rolling passes/No. & 0 & 1 & 2 & 3 & 4 \\
Thickness/mm & 27.0 & 18.9 & 11.3 & 9.0 & 7.2 \\
Reduction/mm & & 8.1 & 7.6 & 2.3 & 1.8 \\
Pass reduction rate/\% & & 30 & 40 & 20 & 20 \\
Repeated reduction rate/\% & 30 & 58 & 67 & 74 \\
Rolling temperature $/{ }^{\circ} \mathrm{C}$ & & 1,050 & 1,000 & 930 & 810 \\
\hline
\end{tabular}

steel increase as the FRT decreases. If FRT is under this critical temperature, the banded microstructure appears which greatly reduces toughness.
In view of the results mentioned above, the hot simulated rolled specimens, which are treated by optimizing TMCP parameters (the start heating temperature, FRT, FCT and cooling rate are $1,180{ }^{\circ} \mathrm{C}, 810{ }^{\circ} \mathrm{C}, 400{ }^{\circ} \mathrm{C}$ and $35{ }^{\circ} \mathrm{C} / \mathrm{s}$, respectively), possess the microstructures that are mainly composed of GB, AF, LB and MA. The HRB value is maximized and may possess the desired mechanical properties. This set of parameters is proposed in the pilot rolling experiment for the development of an X100 pipeline steel.

\subsection{Pilot rolling experiment}

The initial and final thicknesses of the steel plates were $27 \mathrm{~mm}$ and $7.2 \mathrm{~mm}$, respectively, and the total rolling reduction ratio was $73.3 \%$. Then the optimum processing
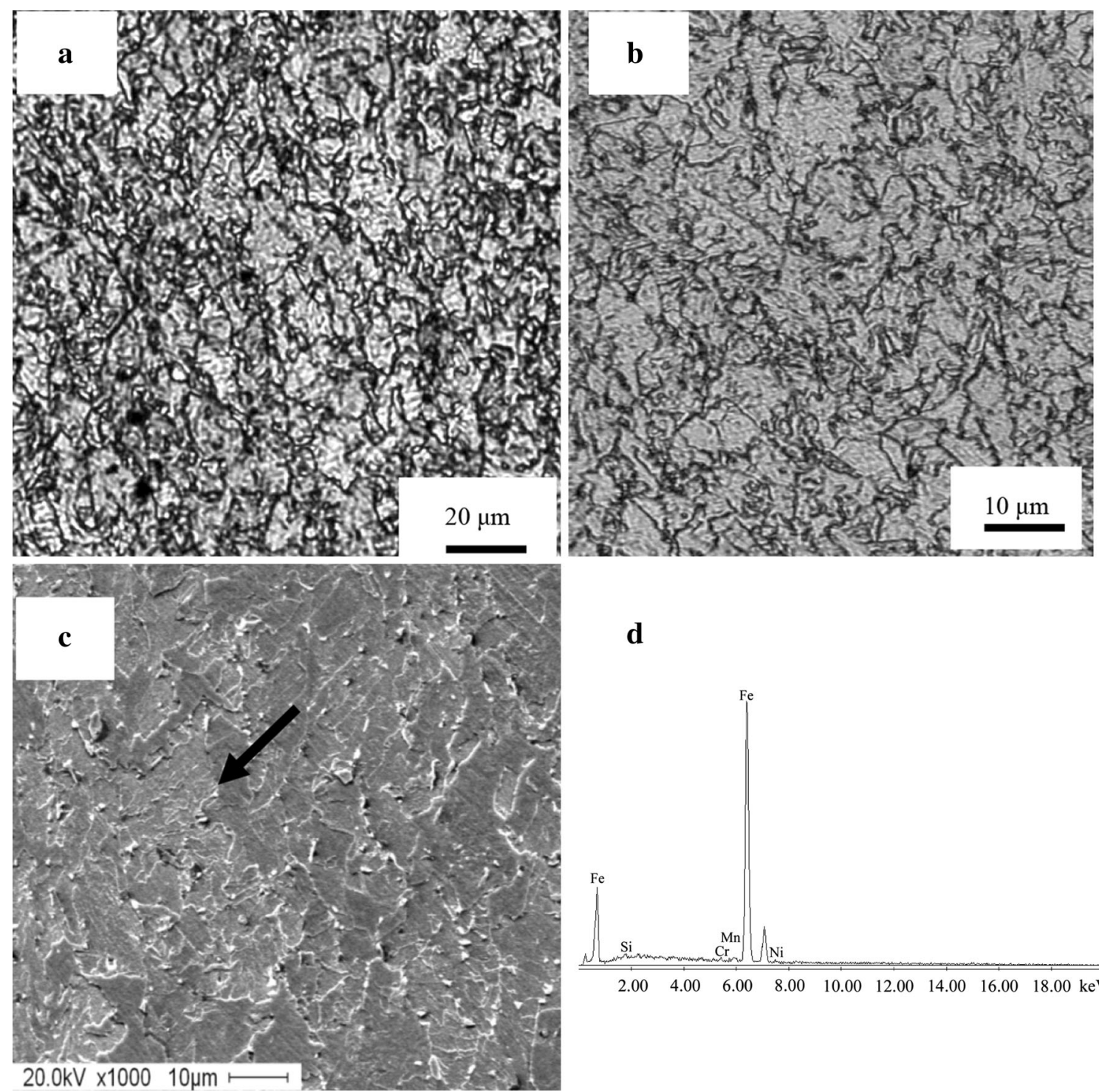

d

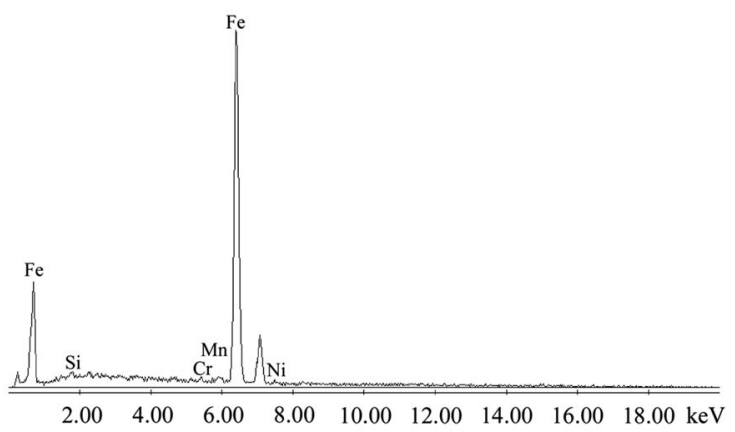

Fig. 3 The microstructure of pilot hot rolled samples (a-d): a, b OM micrographs, c the SEM micrograph, $\mathbf{d}$ EDS analysis 
parameters of TMCP obtained from orthogonal experiment were used in the rolling experiment conducted in the laboratory. The specimen was heated at $1,180{ }^{\circ} \mathrm{C}$ for $30 \mathrm{~min}$. It was finally rolled at $810^{\circ} \mathrm{C}$ through a two-stage controlled rolling process. Then the hot rolled plate was immediately cooled at a controlled cooling rate of $35^{\circ} \mathrm{C} / \mathrm{s}$ and about $400{ }^{\circ} \mathrm{C}$. Table 4 lists the inter-pass reduction distribution for the hot rolling experiment.

Figure 3 shows the microstructure of pilot hot rolled samples.

Table 5 lists the mechanical properties of pilot hot rolled samples.

Microstructures of the hot rolled specimens, with TMCP parameters of the start heating temperature, FRT, FCT and the cooling rate of $1,180{ }^{\circ} \mathrm{C}, 810^{\circ} \mathrm{C}, 400{ }^{\circ} \mathrm{C}$ and $35^{\circ} \mathrm{C} / \mathrm{s}$, respectively, were observed by $\mathrm{OM}$, as shown in Fig. 3. The microstructures of all specimens are mainly composed of GB, LB and AF colonies. Polygonal ferrite was not found and the grain size in the microstructure was fine, as shown in Fig. 3a. At this condition, the amount of AF decreases and GB increases in volume (GB can be clearly seen). The AF colonies appear in isolation, and the relatively small amounts that cannot be easily identified [20], as seen in Fig. 3b. The microstructures were also observed by SEM and were composed of ferrite and bainite colonies, which were homogeneously dispersed. The ferrite is platelike in shape. The width of the plate was $3-5 \mu \mathrm{m}$, and its length is 6 times of its width (see Fig. 3c). Moreover, the dislocation density of the samples is much high in the plate. The precipitates are mainly $\mathrm{Ni}, \mathrm{Mn}$ carbonitrides (see Fig. 3d), which may be formed in the non-recrystallization zone as a result of rolling strain induced precipitation.

The performance of the steel treated by this set of TCMP parameters is shown in Table 4. The average tensile strength is up to $557 \mathrm{MPa}$; the ratio of tensile strength to yield strength is 0.89 ; the Charpy impact work at $20{ }^{\circ} \mathrm{C}$ is $371 \mathrm{~J}$; the elongation is $21.3 \%$. Although the microstructure consists of $\mathrm{GB}, \mathrm{LB}$ and $\mathrm{AF}$, it does not meet the requirement of the $\mathrm{X} 100$ pipeline steel mechanical property [21]. As we know, the cooling system (cooling rate, FCT, FRT) is one of the key factors that decide the property and the constitution of microstructure of the X100 pipeline steel [22, 23]. In our previous work,

Table 5 Results of mechanical properties of pipeline steel

\begin{tabular}{llllll}
\hline $\begin{array}{l}\text { No. of } \\
\text { samples }\end{array}$ & $\begin{array}{l}\sigma_{\mathrm{s}} / \\
\mathrm{MPa}\end{array}$ & $\begin{array}{l}\sigma_{\mathrm{b}} / \\
\mathrm{MPa}\end{array}$ & $\begin{array}{l}\text { Elongation/ } \\
\%\end{array}$ & $\begin{array}{l}\text { Charpy impact } \\
\text { energy/J }\end{array}$ & $\begin{array}{l}\sigma_{\mathrm{s}} / \\
\sigma_{\mathrm{b}}\end{array}$ \\
\hline 1 & 512 & 563 & 20 & 360 & 0.91 \\
2 & 489 & 550 & 21 & 375 & 0.89 \\
3 & 487 & 560 & 23 & 380 & 0.87 \\
Average & 496 & 557 & 21.3 & 371 & 0.89 \\
\hline
\end{tabular}

we designed three other factors and three levels orthogonal experiment with the cooling system factors to discuss its effect on comprehensive properties of X100 pipeline. We found that the FCT played a major role [24]. The FCT is easily controlled and will be investigated in details in order to improve the property of this steel and finally produce the steel which can reach the standard of X100 pipeline.

\subsection{Optimization of FCT}

The plates with sizes as mentioned above are divided into three groups and are rolled using the same controlled rolling process, as shown in Table 3 . The only difference is the final temperature, as shown in Table 6.

The performance of steel with the different FCTs is listed in Table 7, and its effect on the mechanical property of specimens is shown in Figs. $4 \mathrm{a}-\mathrm{e}$.

Microstructures of specimens with the different FCTs are shown in Figs. 5, 6 and 7.

Figure 4 shows the relationship between the mechanical property of the steel and the FCT. From Figs. 4a, b, it can be seen that the tensile strength and yield strength of the steel decrease when the FCT increases, and the elongation and impact energy also increase (see Figs. 4c, d).

When the temperature is at $250{ }^{\circ} \mathrm{C}$, the tensile strength and yield strength are $817 \mathrm{MPa}$ and $719 \mathrm{MPa}$, respectively. The impact energy is $232 \mathrm{~J}$ and the elongation rate was more than $16 \%$. It cannot satisfy the requirements of plasticity and toughness of the X100 pipeline steel. The impact energy at the room temperature can be improved by increasing the FCT. When the temperature increases from $250{ }^{\circ} \mathrm{C}$ to $350{ }^{\circ} \mathrm{C}$, the impact energy increases from $232 \mathrm{~J}$ to $262 \mathrm{~J}$. Meanwhile the yield strength was $695 \mathrm{MPa}$; the

Table 6 The three TMCP samples with different FCTs

\begin{tabular}{lllll}
\hline Samples & $\begin{array}{l}\text { FRT/ } \\
{ }^{\circ} \mathrm{C}\end{array}$ & $\begin{array}{l}\text { The finish rolling } \\
\text { elongation/\% }\end{array}$ & $\begin{array}{l}\text { Cooling rate/ } \\
\left({ }^{\circ} \mathrm{C} \cdot \mathrm{s}^{-1}\right)\end{array}$ & $\begin{array}{l}\text { FCT/ } \\
{ }^{\circ} \mathrm{C}\end{array}$ \\
\hline 1 & & & & 450 \\
2 & 810 & 20 & 35 & 350 \\
3 & & & & 250 \\
\hline
\end{tabular}

Table 7 Mechanical properties of specimens with different FCTs

\begin{tabular}{llllll}
\hline $\begin{array}{l}\text { FCT/ } \\
{ }^{\circ} \mathrm{C}\end{array}$ & $\begin{array}{l}\sigma_{\mathrm{s}} / \\
\mathrm{MPa}\end{array}$ & $\begin{array}{l}\sigma_{\mathrm{b}} / \\
\mathrm{MPa}\end{array}$ & $\begin{array}{l}\text { Elongation/ } \\
\%\end{array}$ & $\begin{array}{l}\text { Charpy impact } \\
\text { energy/J }\end{array}$ & $\begin{array}{l}\sigma_{\mathrm{s}} / \\
\sigma_{\mathrm{b}}\end{array}$ \\
\hline 250 & 743 & 817 & 14.3 & 232 & 0.91 \\
350 & 695 & 768 & 16.6 & 262 & 0.89 \\
450 & 662 & 719 & 23.4 & 274 & 0.92 \\
\hline
\end{tabular}



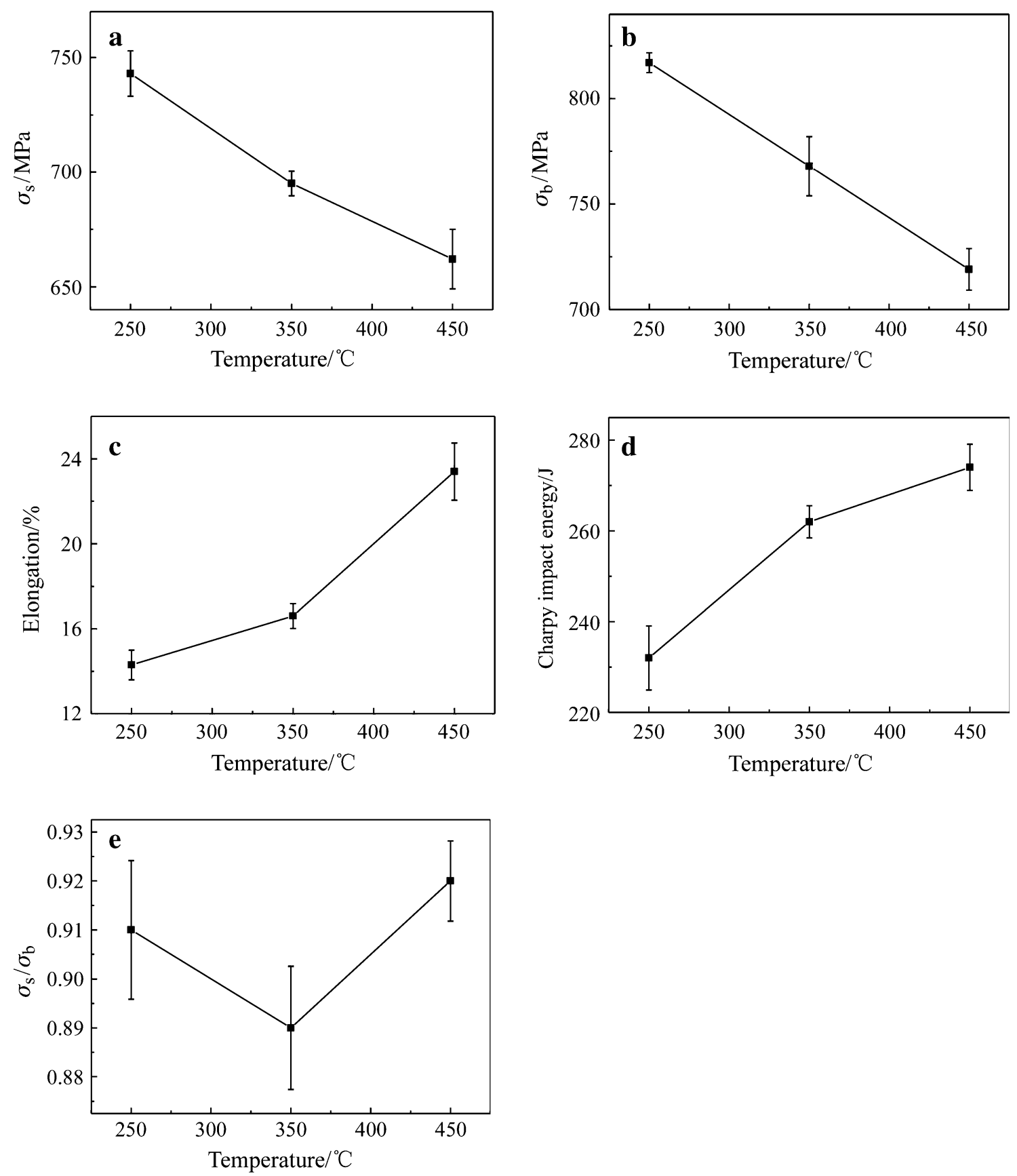

Fig. 4 The mechanical property of the steel with the FCTs $\left(250{ }^{\circ} \mathrm{C}, 350{ }^{\circ} \mathrm{C}, 450{ }^{\circ} \mathrm{C}\right)$

tensile strength was $768 \mathrm{MPa}$; the elongation was $16.6 \%$. All indices can satisfy performance requirements of X100 pipeline steel. With the further increase of the FCT $\left(450{ }^{\circ} \mathrm{C}\right)$, the elongation and impact energy are obviously increased, and the toughness is improved. However, its strength becomes lower and cannot meet the requirements of X100 pipeline steel.

Figures 5, 6 and 7 show the optical micrographs of the specimens at FCT of $450{ }^{\circ} \mathrm{C}, 350{ }^{\circ} \mathrm{C}$ and $250{ }^{\circ} \mathrm{C}$, respectively. From Fig. 5, it can be seen that, at the FCT of
$450{ }^{\circ} \mathrm{C}$, the GB transformation occurs completely, therefore there exist lots of GB. This microstructure may result to the obvious decrease of the strength and the increase of the toughness of samples.

Figure 6 shows the microstructure of the steel at the FCT of $350{ }^{\circ} \mathrm{C}$, which is mainly composed of GB and AF. As a result, the prior austenite grains are effectively separated, and the growth of lath-like is restricted in the separated zones. Hence the excessive growth of lath-like is limited and the grain orientation is not obvious. The 

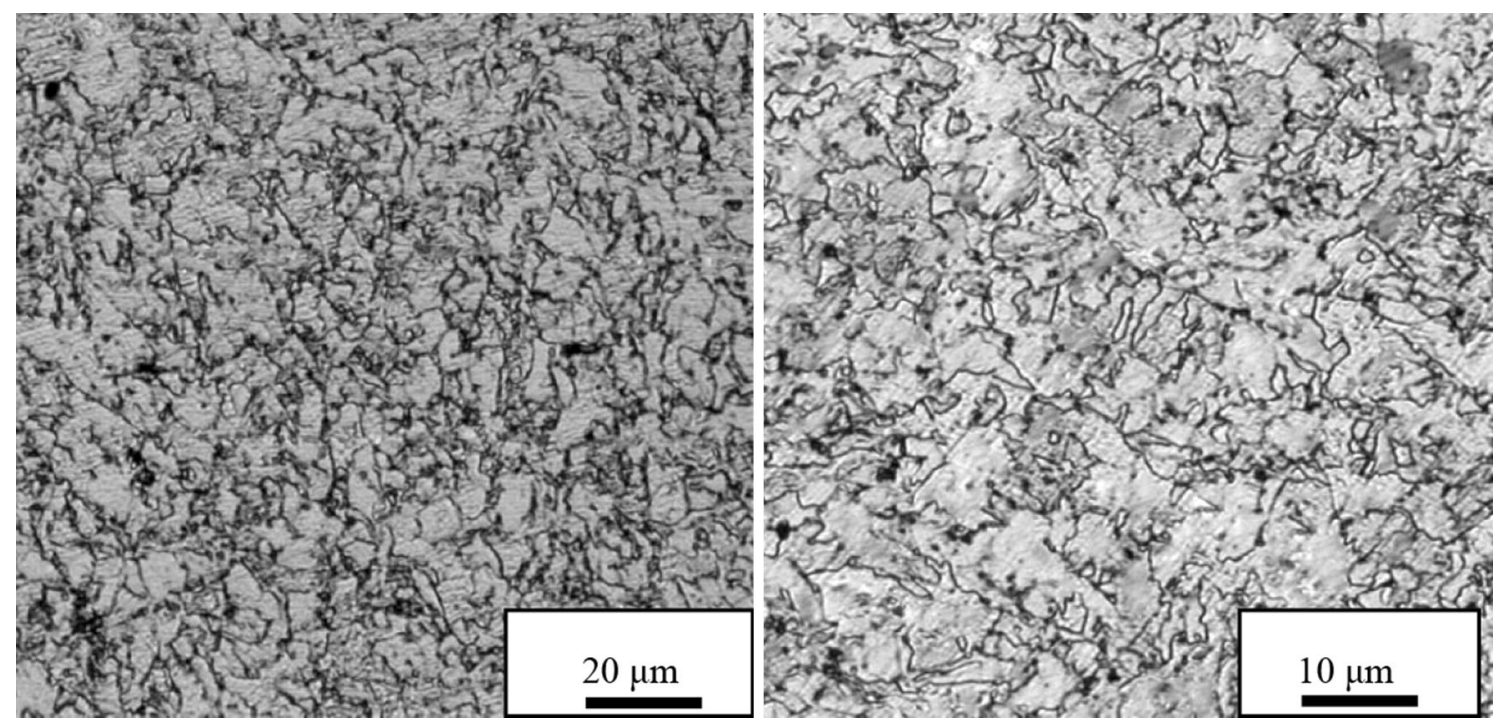

Fig. 5 The optical micrographs of the specimens at the FCT of $450{ }^{\circ} \mathrm{C}$
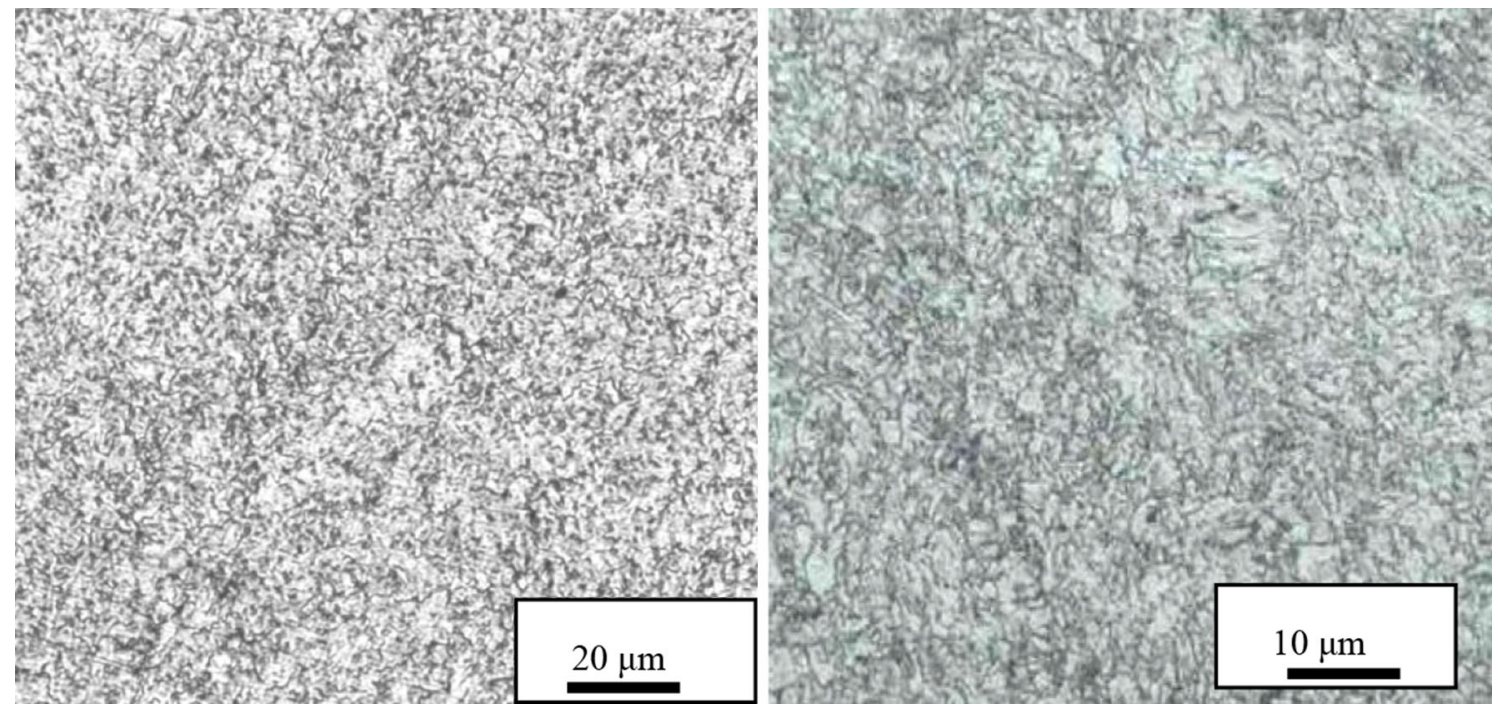

Fig. 6 The optical micrographs of the specimens at the FCT of $350{ }^{\circ} \mathrm{C}$

effective grain sizes become smaller and fall below $20 \mu \mathrm{m}$, and the steel possesses the optimal refinement microstructure. Compared to the specimens at FCT of $450{ }^{\circ} \mathrm{C}$ and $250{ }^{\circ} \mathrm{C}$, these specimens reach the best balance between the strength and the toughness due to the occurrence of the refinement microstructure.

At the FCT of $250{ }^{\circ} \mathrm{C}$, the microstructures of the specimens are composed of the lathbainite and martensite $(\mathrm{LB}+\mathrm{M})$, as shown in Fig. 7. The orientation of lath-like in the prior austenite grain is relatively simple, which runs through the austenite grain at the length direction of lath, and the part of boundaries become unclear. However the boundaries between the laths are clear and the lath characteristics are more obvious. The characteristics of massive transformation exist at the local zone. The effective grain sizes become larger and increase to above $30 \mu \mathrm{m}$ in general. This fact may cause the high strength and poor plasticity and toughness of specimens.

\section{Conclusions}

(i) The X100 pipe steel developed in this study is studied by the Gleeble- 3500 hot simulator as well as the orthogonal experiment design. The microstructures mainly composed of GB, AF, LB and MA are observed by this set of TCMP. The start heating temperature, FRT, FCT and the 

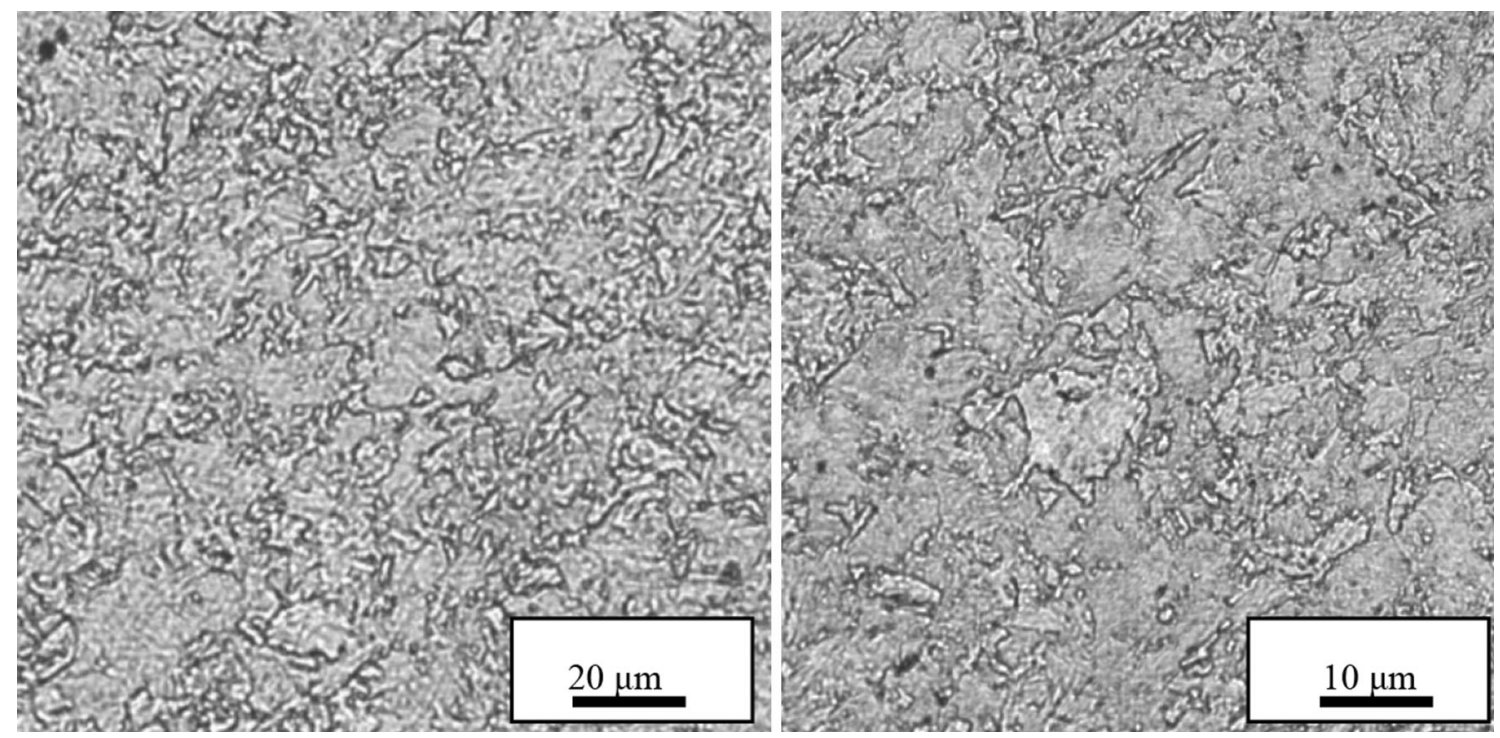

Fig. 7 The optical micrographs of the specimens at the FCT of $250{ }^{\circ} \mathrm{C}$

cooling rate of $1,180{ }^{\circ} \mathrm{C}, 810{ }^{\circ} \mathrm{C}, 400{ }^{\circ} \mathrm{C}$ and $35^{\circ} \mathrm{C} / \mathrm{s}$, respectively. Its $\mathrm{HRB}$ value is maximized.

(ii) The optimized TCMP parameters mentioned above are used in the pilot rolling experiment. The results show that the average tensile strength can be up to $557 \mathrm{MPa}$, and the ratio of tensile strength to yield strength is 0.89 . The Charpy impact work at $20^{\circ} \mathrm{C}$ can be up to $371 \mathrm{~J}$, and the elongation can reach $21.3 \%$. Observed by using $\mathrm{OM}$ and SEM, its microstructure consists of GB, $\mathrm{LB}$ and $\mathrm{AF}$.

(iii) The FCT is investigated in details meanwhile other factors are kept unchanged. With the increase of FCT, the strength of the experiment steel decreases and both the elongation and Charpy impact energy increase. When the FCT is $350{ }^{\circ} \mathrm{C}$, the steel reaches the optimal balance between the strength and the toughness.

(iv) For the steel thermo-mechanically treated by this set of parameters(the start heating temperature, FRT, FCT and cooling rate of $1,180{ }^{\circ} \mathrm{C}, 810^{\circ} \mathrm{C}$, $350{ }^{\circ} \mathrm{C}$ and $35^{\circ} \mathrm{C} / \mathrm{s}$, respectively), the microstructures are mainly composed of $\mathrm{GB}$ and $\mathrm{AF}$, this is the optimal microstructure.

\footnotetext{
Acknowledgments The authors thank the National Nature Science Foundation of China (Grant Nos. 51374142, 51225401), the Science and Technology Fund of Scientific Committee of Shanghai (Grant Nos. 11520500100, 11DZ2283400) and the Open Project of the State Key Laboratory of New Ferrous Metallurgy Technology (Grant No. KF12-05).
}

\section{References}

1. Wang YK, Pan JH, Yang K, et al (2007) In: Proceedings of international symposiumon microalloyed steels for the oil and gas industry. pp 135-179

2. Hillenbrand HG, Kalwa C (2002) Production and service behavior of high strength large diameter pipes. In: Toyoda M, Denys $\mathrm{R}$ eds. Proceedings of international conference on the application and evaluation of high-grade linepipes in hostile environments. Scientific Surveys Ltd., Yokohama, pp 203-215

3. Okaguchi S (2005) Production and development of linepipe steel in grade X100 and X120. In: International forum of X100/X120 high strength line pipe. Beijing, 2005

4. Haiwen L, Han D (2006) Development of X80-X120 high grade linepipe steels and their applications. J China Metall 16(4):9-15

5. Gómez M, Valles P, Medina SF (2011) Evolution of microstructure and precipitation state during thermo mechanical processing of a X80 microalloyed steel. J Mater Sci Eng A528(13-14):4761-4773

6. Hillenbrand HG, Amoris E, Niederhoff KA(1995) Manufacrurability of linepipe in grads up to $\mathrm{X} 100$ from TM processed plate $\mathrm{C}$ pipeline technology conference

7. Wang G (2012) Development of a new generation TMCP technology. J Steel Rolling 29(1):1-7

8. Hitoshi A, Takuya H et al (2004) Development of ultra-highstrength linepipe X120. J Nippon Steel Tech Rep 9:82-88

9. Wang CM, Wu XF, Liu J (2006) Transmission electron microscopy of martensite/austenite islands in pipeline steel X70. J Mater Sci Eng A440:267-271

10. Huilin GA (2009) Pipeline steel alloy design and its research progress. J Welded Pipe Tube 11:5-12

11. Wang C, Lu Q (2004) Alloy design for pipeline steel. J Angang Technol 6:22-28

12. Gerry P, Michael J, Keough (2002) Experimental design and data analyses for biologists. Cambridge University Press, Cambridge

13. State Bureau of Quality and Technical Supervision, GB/T 1172 (1999) Conversion of hardness and strength for ferrous metal. Standards Press of China, Beijing 
14. Liang D, Zhu Y, Zhou L et al (2011) Acicular ferrite and its heterogeneous nucleation mechanism in steels. J Heat Treat Metals 36(12): 105-110

15. Kimura Y, Takaki S (1997) Phase transformation mechanism of Fe-Cu alloys. ISIJ Int 37(3):290-295

16. Linna L, Yu C, Liu Q et al (2014) Effect of thermo-mechanical control process on microstructure of high strength X100 pipeline steel. J Chin J Mater Res 28(1):51-57

17. Shang CJ, Wang XM (2005) Microstructure and mechanical properties of low carbon bainitic. J Steel Iron Steel 40(4):57

18. Keehyun K, Nongmoon H, Byungjoo L et al (2005) Effect of the finish rolling temperature on mechanical properties and microstructure evolution of linepipesteel. Mater Sci Forum, 475-479:89-92

19. Phillips R, Chapman JA (1966) Influence of finish rolling temperature on mechanical properties of some commercial steels rolled to 13/16 in diameter bars. J Iron Steel Institute 204: 615-620
20. Fang HS, Yang ZG, Yang JB (2005) Research on bainite transformation in steels. J Acta Metall Sin 41(5):449

21. Rodrigues PCM, Pereloma EV, Santoc DB (2000) Mechanical properties of an HSLA bainitic steel subjected to controlled rolling with accelerated rolling. J Mater Sci Eng 283A(6): 136-143

22. Wiskel JB, Ivey DG, Henein H (2008) The effects of finish rolling temperature and cooling interrupt conditions on precipitation in microalloyed steels using small angle neutron scattering. J Mater Sci Eng B 39:116

23. Jiang M, Chen L, Pang W (2012) Thermal-mechanical simulation of the controlled rolling and cooling process by orthogonal design for pipeline steel. J Adv Mater Res 3:2355-2360

24. Chen L, Jiang M, Zhou F et al (2012) Optimization and testing for controlled rolling and cooling process by orthogonal design. J Chin Soc Rare Earths 30:834-837 